\title{
Comparison of Astigmatism in Combined SICS and Trabeculectomy by Sutureless Technique vs. Combined SICS and Tabeculectomy Surgery with 'W' Shaped Incision Technique
}

\author{
Authors \\ Dr Shikha Agarwal ${ }^{1}$, Dr Priyanka Jain ${ }^{2 *}$
}

${ }^{1}$ Assistant Professor, Ophthalmology, Mayo Institute of Medical Sciences, Barabanki, Uttar Pradesh

${ }^{2}$ Assistant Professor, Ophthalmology, Mulayam Singh Yadav Medical College, Meerut, Uttar Pradesh

*Corresponding Author

Dr Priyanka Jain

Department or Institution to which the work should be attributed- Mayo Institute of Medical Sciences,

Barabanki, Uttar Pradesh, India

\begin{abstract}
To decrease astigmatism in cataract as well as trabeculectomy different modification have been tried in the incision shape, size and sites. Sutureless trabeculectomy and ' $W$ ' shaped incision trabeculectomy is also few of them. A randomized, prospective, interventional and comparative clinical trial carried out on 39 eyes of 39 patients with primary open angle glaucoma (POAG) with coexisting cataract. The aim of the study was to compare the astigmatism of combined manual Small-Incision Cataract Surgery (SICS) and posterior chamber intraocular lens (PCIOL) implantation with Trabeculectomy by sutureless [group A] versus combined SICS and PCIOL implantation with trabeculectomy using ' $W$ ' shaped incision technique [group B]. Surgically induced ATR Astigmatism in group A was $1.57 \pm 0.37 D$ while in group B was $1.28 \pm 0.39 D$ $[p=0.028]$. None of the patient in either group had surgically induced WTR astigmatism. Due to the high mechanical stability of the W-shaped incision and suture, comparatively less induced astigmatism was seen in combined surgery done with W- shaped incision in comparison to combined SICS with sutureless trabeculectomy. Both the procedures are safe as none of the patient in any group had any major complication or sight loss due to surgery

Keywords: Astigmatism, cataract, glaucoma, trabeculectomy, sutureless, 'W' shaped incision.
\end{abstract}

\section{Introduction}

Inducing some astigmatism is to be expected during cataract surgery, but with typical cataract incisions it's becoming smaller and smaller. Surgically induced astigmatism is the change in both the power and to a lesser degree, the orientation of the principal meridians following a corneal incision, ${ }^{[1] "}$ To decrease astigmatism in cataract as well as trabeculectomy different modification have been tried in the incision shape, size and sites and few of them found to be more useful in comparison to conventional surgery. Frown shaped incision gained much popularity in this aspect. Sutureless trabeculectomy is also one of them. Another modification described was ' $W$ ' shaped incision trabeculectomy. Very few studies 
have done in ' $\mathrm{W}$ ' shaped incision technique so we performing one of them.

The aim of the study was to compare the astigmatism of combined manual Small-Incision Cataract Surgery (SICS) and posterior chamber intraocular lens (PCIOL) implantation with Trabeculectomy by sutureless versus combined SICS and PCIOL implantation with trabeculectomy using ' $\mathrm{W}$ ' shaped incision technique

\section{Materials and Methods}

A randomized, prospective, interventional and comparative clinical trial carried out on 39 eyes of 39 patients attending outpatient department and glaucoma clinic

Inclusion criteria patients with primary open angle glaucoma (POAG) with coexisting cataract.

Exclusion criteria The patients with any other associated ocular disease, with previous ocular surgery or trauma and with diagnosed cases of angle closure and secondary glaucoma

Detailed history regarding diminution of vision, headache or eye ache, colored haloes, dark spots in the field of vision, redness, and photophobia, family history of glaucoma and history of drug intake was recorded. Any systemic illness and past history in relation to any ocular trauma, surgery, laser treatment or medications were enquired about.

Ocular examination Best Corrected Visual Acuity (BCVA, slit-lamp examination, applanation tonometry, gonioscopy, automated perimetry, keratometry \& biometry.

The patients were randomly divided into two groups (A \& B). Group A $(n=19)$ included patients who underwent combined SICS with sutureless trabeculectomy. Group B $(n=20)$ included the patients who underwent combined SICS with 'W'-shaped incision trabeculectomy with one suture.

\section{Surgical procedure}

1. A fornix-based conjunctival flap was made at the limbus from 10 o'clock to 2 o' clock
Group A- A partial thickness 'V' shaped sclera groove of $6 \mathrm{~mm}$ size was made superiorly $2 \mathrm{~mm}$ away from the limbus. \& a scleral tunnel was dissected followed by routine SICS with PCIOL implantation

Group B- A partial thickness 'W'-shaped scleral groove was made superiorly $2 \mathrm{~mm}$ away from the limbus. A triangular flap was lifted with base towards the limbus followed by routine SICS with PCIOL implantation.

Group A- Kelly's punch was used to punch out a piece of trabecular meshwork at the posterior limbus within the scleral tunnel.

Group B- The central triangular part of the W shaped scleral flap was lifted and a block of deep sclera $(1.5 \times 2 \mathrm{~mm})$ was excised using a razor blade fragment and corneal scissors. A peripheral iridectomy was done. The superficial triangular scleral flap was sutured by one 10 - 0 nylon suture at the apex of the flap.

The conjunctival flap was repositioned back and sutured with 10-0 nylon suture in both the groups.

Post operative assessment of the Patients was done on day $1,3,7$; then at $2^{\text {nd }}$ week, $4^{\text {th }}$ week, $8^{\text {th }}$ week and then monthly till the end of study august 2011- July 2012.

Statistical analysis: Student's unpaired ' $t$ ' test and chi square test were used to data with the help of SPSS 21 software

\section{Results}

Mean age of the patient in group $A$ was $63.74 \pm 5.94$ years and in group B was $64.30 \pm 6.02$ years $(p$ value $=0.77)$. $\mathrm{F}$ : F ratio was $1.78: 1$. The mean follow up time for group A was $8.42 \pm 2.01$ months and for group B was $8.47 \pm 2.01$ months $(p=0.93)$.

In group A mean preoperative BCVA was $1.034 \pm$ $0.46 \log$ MAR In group B mean preoperative $\mathrm{BCVA}$ was $0.980 \pm 0.33 \log \mathrm{MAR}$ ( $p$ value $=$ 0.65). In group A mean postoperative BCVA was $0.665 \pm 0.39 \log$ MAR \& in group $\mathrm{B}$ mean postoperative BCVA was $0.662 \pm 0.36 \log$ MAR $(p$ value $=0.98)$.

Preoperative mean WTR (With the Rule) 
astigmatism in group A was $0.88 \pm 0.30 \mathrm{D}$ and in group $\mathrm{B}$ was $0.94 \pm 0.37 \mathrm{D}$ ( $p$ value 0.72 ). Preoperative mean ATR (Against the Rule) astigmatism in group A was $0.93 \pm 0.37 \mathrm{D}$ and in group B was $0.94 \pm 0.39 \mathrm{D}$ ( $p$ value 0.95) (table 1 ). None of the patient had post operative WTR astigmatism in group A while in group B one patient had WTR astigmatism (table 2). None of the patient in either group had surgically induced WTR astigmatism (table 3).

Table 1 Pre op Astigmatism

\begin{tabular}{|l|c|c|c|c|}
\hline \multirow{2}{*}{$\begin{array}{l}\text { Pre op } \\
\text { Astigmatism } \\
\text { (Diopters) }\end{array}$} & \multicolumn{2}{|c|}{$\begin{array}{c}\text { Group A } \\
\text { (no. of eyes) }\end{array}$} & \multicolumn{2}{c|}{$\begin{array}{c}\text { Group B } \\
\text { (no. of eyes) }\end{array}$} \\
\cline { 2 - 5 } & WTR & ATR & WTR & ATR \\
\hline 0.25D & 0 & 0 & 0 & 1 \\
\hline 0.50D & 2 & 2 & 2 & 2 \\
\hline 0.75D & 2 & 4 & 2 & 3 \\
\hline 1.00D & 2 & 2 & 1 & 3 \\
\hline 1.25D & 2 & 2 & 1 & 2 \\
\hline 1.50D & 0 & 0 & 1 & 2 \\
\hline 1.75D & 0 & 1 & 0 & 0 \\
\hline 2.00D & 0 & 0 & 0 & 0 \\
\hline >2.00D & 0 & 0 & 0 & 0 \\
\hline Mean & $0.88 \pm 0.30 \mathrm{D}$ & $0.94 \pm 0.37 \mathrm{D}$ & $0.93 \pm 0.37 \mathrm{D}$ & $0.94 \pm 0.39 \mathrm{D}$ \\
\hline $\begin{array}{l}\text { Test of } \\
\text { ignificance }\end{array}$ & \multicolumn{2}{|c|}{$p=0.72$} & \multicolumn{2}{c|}{$p=0.95$} \\
\hline
\end{tabular}

Table 2 Post op Astigmatism

\begin{tabular}{|l|c|c|c|c|}
\hline \multirow{2}{*}{$\begin{array}{l}\text { Post op Astigmatism } \\
\text { (Diopters) }\end{array}$} & \multicolumn{2}{|c|}{$\begin{array}{c}\text { Group A(n=19) } \\
\text { (no. of eyes) }\end{array}$} & \multicolumn{2}{c|}{$\begin{array}{c}\text { Group B(n=20) } \\
\text { (no. of eyes) }\end{array}$} \\
\cline { 2 - 5 } & WTR & ATR & WTR & ATR \\
\hline 0.25D & 0 & 2 & 0 & 2 \\
\hline 0.50D & 0 & 3 & 1 & 1 \\
\hline 0.75D & 0 & 2 & 0 & 1 \\
\hline 1.00D & 0 & 0 & 0 & 2 \\
\hline 1.25D & 0 & 0 & 0 & 1 \\
\hline 1.50D & 0 & 0 & 0 & 1 \\
\hline 1.75D & 0 & 2 & 0 & 3 \\
\hline 2.00D & 0 & 2 & 0 & 2 \\
\hline 2.25D & 0 & 1 & 0 & 2 \\
\hline 2.50D & 0 & 2 & 0 & 2 \\
\hline 2.75D & 0 & 3 & 0 & 1 \\
\hline 3.00D & 0 & 0 & 0 & 0 \\
\hline$>$ 3.00D & 0 & 2 & 0 & 1 \\
\hline
\end{tabular}

Table 3 Surgically induced Astigmatism

\begin{tabular}{|l|c|c|c|}
\hline \multirow{2}{*}{$\begin{array}{l}\text { Surgically } \\
\text { induced } \\
\begin{array}{l}\text { Astigmatism } \\
\text { (Diopters) }\end{array}\end{array}$} & \multicolumn{2}{|c|}{$\begin{array}{c}\text { shifting to ATR } \\
\text { (no. of eyes) }\end{array}$} & $\begin{array}{c}\text { Shifting to } \\
\text { WTR } \\
\text { (no. of eyes) }\end{array}$ \\
\cline { 2 - 4 } 0.25D & 0 & Group B & 0 \\
\hline 0.5D & 0 & 0 & 0 \\
\hline .75D & 0 & 1 & 0 \\
\hline 1.0D & 2 & 2 & 0 \\
\hline 1.25D & 4 & 6 & 0 \\
\hline 1.5D & 6 & 6 & 0 \\
\hline 1.75D & 3 & 2 & 0 \\
\hline 2.0D & 2 & 1 & 0 \\
\hline 2.25D & 2 & 0 & 0 \\
\hline 2.5D & 0 & 0 & 0 \\
\hline 2.75D & 0 & 0 & 0 \\
\hline 3.0D & 0 & 0 & 0 \\
\hline Mean & $1.57 \pm 0.37 D$ & $1.28 \pm 0.39 D$ & - \\
\hline $\begin{array}{l}\text { Test } \\
\text { significance }\end{array}$ & \multicolumn{2}{|c|}{ value $=\mathbf{0 . 0 2 8}$} \\
\hline
\end{tabular}

\section{Discussion}

Out of all glaucoma surgery trabeculectomy is the best technique to be used in association with cataract extraction (Brégeat $\mathrm{P}$ et al., 1974) ${ }^{[2]}$ because the protective scleral flap over a limbal fistula reduces the chances of an early postoperative flat anterior chamber and also makes the guarded filtering operation particularly desirable for combined procedures. Corneal astigmatism following cataract extraction is now well recognized. There is an increase in the vertical corneal radius of curvature. In contrast in trabeculectomy there occurs a reduction in the corneal radius in the vertical meridian. The reason of this difference may be the result of partial thickness scleral flap created during trabeculectomy. The surgically produced gap is overlaid by a scleral flap, which spreads support from the sutures inserted into it over the whole of the wound gape. The more posterior placement of the incision may also explain the difference in behaviour in comparison with cataract extraction [3].

In the result, both group showed improvement in post operative BCVA ( $p$ value $=0.98$ ). Difference in time taken to achieve BCVA in both groups was not calculated statistically. glaucoma was the prime reason for diminution of vision, final BCVA had little or no change. The improvement in final BCVA is analogous with other studies. Hornová J. (1997) $)^{[4]}$; Dittmer K (1998) ${ }^{[5]}$ also found that vision improvement by combine 
surgery. Post operatively the mean surgically induced astigmatism distribution was towards the ATR astigmatism. kelly descement punch was the scheme of sclerostomy used in group A and a variety of these are available. There is evidence that a small sclerostomy $(0.5 \mathrm{~mm})$ may lessen astigmatism. Surgically-induced astigmatism observed in the present study in Group A patients was almost comparable to that reported in most of the combined surgeries. However, a comparatively less induced astigmatism was seen in Group B which may be due to the high mechanical stability of the $\mathrm{W}$-shaped incision and sutures which leaded improved healing of incision site. The side cuts used in $\mathrm{W}$ shaped incision was the major factor for reduction or neutralization of astigmatism. Although no suture material was used in group A but this was not found to be favorable for reduction of astigmatism. These results are also consistent with previous studies done on $\mathrm{W}$-shaped incision by various authors. All of them appreciated the high mechanical stability of the $\mathrm{W}$ - shaped which in turn reduces the astigmatism. Because the $\mathrm{W}$ incision can be regarded as a self sealing incision with an additional posterior flap, for cataract surgery, the flap can be used to add further stability to the incision. The $\mathrm{W}$ incision offers high stability and multiple advantages over the frown incision and is suitable for use with rigid posterior chamber IOLs (Michielsens A \& Hennekes R, 1994) ${ }^{[6]}$. As concluded by Pantelis et al. (1994) W-shaped incision improves the control of astigmatism and self-sealing characteristics, has a high mechanical stability, and is easily extendible for extracapsular cataract extraction (ECCE) or trabeculectomy ${ }^{[7]}$.In study by Khurana A.K. et al.(2011) the mean induced astigmatism in Group of patients sutureless trabeculectomy combined with SICS was $1.48 \pm 0.38 \mathrm{D}$ ATR and in Group of patients $\mathrm{W}$ shape incision trabe with SICS $1.15 \pm 0.52 \mathrm{D}$ $\mathrm{ATR}^{[8]}$. In study of Nielsen (1997) reported the mean induced astigmatism ranging from -1.9 D ATR to +1.3 D WTR astigmatism at 12 months in cases of combined small incision cataract surgery and trabeculectomy ${ }^{[9]}$.

\section{Conclusion}

Due to the high mechanical stability of the Wshaped incision and suture, comparatively less induced astigmatism was seen in combined surgery done with $\mathrm{W}$ - shaped incision in comparison to combined SICS with sutureless trabeculectomy. There is no advantage in terms of visual performance because the final best corrected visual acuity was same in the both groups. Both the procedures are safe as none of the patient in any group had any major complication or sight loss due to surgery.

Hence our study concludes in a patient of coexisting glaucoma and cataract combined small incision cataract surgery with trabeculectomy using W- shaped incision" is a safer and more effective approach to reduces postoperative astigmatism and complications in comparison to combined small incision cataract surgery with sutureless trabeculectomy.

Acknowledgments- None

Sources of Support in the form of grants- Nil

\section{References}

1. Warren E. Hill, MD, East Valley Ophthalmology, Mesa, Ariz., Source: https://www.eyeworld.org/

2. Bregeat P, [Cataract surgery and trabeculectomy at the same time. klin mobl augenhilkd 1975 Oct; 167 (4):505-15.

3. Hugkulstone CE . Changes in keratometry following trabeculectomy. $\mathrm{Br} \quad \mathrm{J}$ Opthalmol1991; 75: 217-8

4. Hornová J. [Combination surgery (ECCE+IOL+TE) and intraocular pressure levels].Cesk Slov J Oftalmol. 1997 Aug; 53 (4):234 9.

5. Dittmer K, Quentin CD. [Intraocular pressure regulation after combined glaucoma and cataract operation]. Ophthalmologe. 1998 Jul; 95 (7):499-503. 
6. Michielsens A, Henneker R. W-incision for combined cataract and glaucoma surgery. Bull Soc Belge Ophthalmol; (1994) 254: 13-7.

7. Pantelis V, Wijaya J, Hennekes R. Wincision for cataract surgery. Bull Soc Belge Ophthalmol (1994); 254: 19-23.

8. Khurana AK et al Combined SICS and trabeculectomy Nepal J Ophthalmol 2011; 3 ( 5 ): 13-18

9. Nielsen PJ Combined small-incision cataract surgery and trabeculectomy: a prospective study with 1 year of followup.. Ophthalmic surgery lasers Jan 1997; 28 (1):21-9. 